\title{
Motion-correlated flow distortion and wave-induced biases in air-sea flux measurements from ships
}

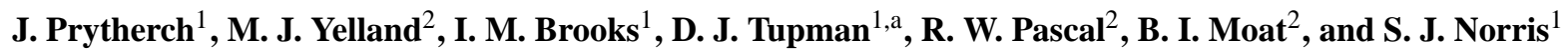 \\ ${ }^{1}$ School of Earth and Environment, University of Leeds, Leeds, UK \\ ${ }^{2}$ National Oceanography Centre, Southampton, UK \\ ${ }^{a}$ now at: Centre for Applied Geosciences, University of Tübingen, Germany
}

Correspondence to: J. Prytherch (j.prytherch@leeds.ac.uk)

Received: 17 April 2015 - Published in Atmos. Chem. Phys. Discuss.: 10 June 2015

Revised: 3 September 2015 - Accepted: 8 September 2015 - Published: 25 September 2015

\begin{abstract}
Direct measurements of the turbulent air-sea fluxes of momentum, heat, moisture and gases are often made using sensors mounted on ships. Ship-based turbulent wind measurements are corrected for platform motion using well established techniques, but biases at scales associated with wave and platform motion are often still apparent in the flux measurements. It has been uncertain whether this signal is due to time-varying distortion of the air flow over the platform or to wind-wave interactions impacting the turbulence. Methods for removing such motion-scale biases from scalar measurements have previously been published but their application to momentum flux measurements remains controversial. Here we show that the measured motion-scale bias has a dependence on the horizontal ship velocity and that a correction for it reduces the dependence of the measured momentum flux on the orientation of the ship to the wind. We conclude that the bias is due to experimental error and that time-varying motion-dependent flow distortion is the likely source.
\end{abstract}

\section{Introduction}

Obtaining direct eddy covariance estimates of turbulent airsea fluxes from ship-mounted sensors is extremely challenging. Measurements of the turbulent wind components must be corrected for the effects of platform motion and changing orientation (Edson et al., 1998; Schulze et al., 2005; Brooks, 2008; Miller et al., 2008). The ship also acts as an obstacle to the air flow forcing it to lift and change speed; this results in both the measured mean wind being biased (accel- erated/decelerated) relative to the upstream flow and the effective measurement height being lower than the instrument height. This can significantly bias estimates of the $10 \mathrm{~m}$ neutral wind speed $\left(U_{10 \mathrm{n}}\right)$ and the surface exchange coefficients (Yelland et al., 1998). Computational fluid dynamics (CFD) modelling studies of the flow distortion have been used to determine corrections for these mean flow distortion effects for a number of different research vessels (Yelland et al., 1998, 2002; Dupuis et al., 2003; Popinet et al., 2004; Moat et al., 2005; O'Sullivan et al., 2013, 2015) and also generic corrections for commercial vessels that report meteorological measurements (Moat et al., 2006a, b).

The modelled corrections show a strong dependence on the relative wind direction (Yelland et al., 2002; Dupuis et al., 2003) and a much weaker dependence on wind speed, but in general they have been determined only for ships with zero pitch and roll angles. Weill et al. (2003) and Brut et al. (2005) reported on experiments with a $1 / 60$ scale physical model of the RV La Thalassa to investigate the effect of pitch and roll angles on the mean flow distortion. They found the tilt of the mean streamline to vary by more than $1^{\circ}$ and the mean wind speed by up to $12 \%$ for pitch angles between $\pm 10^{\circ}$; these effects were asymmetric about zero pitch. Roll angle had only a small impact on the measured wind speed, about $1 \%$ for roll of up to $10^{\circ}$, but this was examined for bow-on flows only and a larger impact might be expected for flows with a significant beam-on component. Comparison of in situ measurements from sonic anemometers, the physical model tests and CFD modelling also revealed that the foremast itself, along with the instruments and electronics enclosures 
mounted on it, had a significant impact on flow distortion at the location of the sonic anemometer.

The studies of flow distortion cited above addressed only the mean flow for a fixed orientation of the ship with respect to the mean streamline; to the best of our knowledge no studies have investigated the effect of time-varying flow distortion as ship attitude changes. That the time-varying flow distortion has an impact can, however, be inferred from reported biases of ship-based eddy covariance measurements. Edson et al. (1998) compared eddy covariance estimates of the kinematic wind stress from two ships with those from a small catamaran and from the stable research platform FLIP. They found that the ship-based estimates were on average $15 \%$ higher than those from FLIP and the catamaran. They argued that the difference resulted from flow distortion over the ship rather than from inadequate motion correction because the catamaran experienced more severe platform motion. Pedreros et al. (2003) similarly found momentum flux estimates from a ship to be $18 \%$ higher than estimates from a nearby air-sea interaction spar buoy. Evidence of such biases, ascribed to flow distortion, led to the exclusion of shipbased direct flux measurements from the most recent update of the COARE bulk air-sea flux algorithm (v3.5; Edson et al., 2013).

Features in cospectra that manifest as significant deviations from the expected spectral form (e.g. Kaimal et al., 1972) at frequencies associated with waves and platform motion have been reported in observations of momentum fluxes measured from FLIP (Miller et al., 2008) and from fixed platforms (Deleonibus, 1971) and towers (Drennan et al., 1999). A decrease in the magnitude of the feature with height led Miller et al. (2008) to ascribe its source to interactions between the waves and atmospheric turbulence. The authors also note that the anemometers used were not co-mounted with inertial motion units and their tilt from horizontal was determined using the planar fit method; errors in the determined tilt or in estimation of anemometer and inertial motion unit alignment could also contribute to the observed features via incomplete correction for platform motion (Brooks, 2008; Landwehr et al., 2015). Edson et al. (2013) analysed wind profile measurements from three field campaigns and found little evidence of wave influence on winds at heights above $4 \mathrm{~m}$ in sea conditions with $c_{\mathrm{p}} / U_{10 \mathrm{n}}<2.5$, where $c_{\mathrm{p}}$ is the wave phase speed. In general, reported motion-scale signals in the turbulence have been observed in measurements made either at heights below $10 \mathrm{~m}$ (Deleonibus, 1971; Miller et al., 2008) or in conditions of fast, high swell where $c_{\mathrm{p}} / U_{10 \mathrm{n}} \approx 2$ and $\mathrm{Hs}_{\text {swell }} \gg \mathrm{Hs}_{\text {wind }}$, and $\mathrm{Hs}_{\text {swell }}$ and $\mathrm{Hs}_{\text {wind }}$ are the significant wave heights of the swell and wind-wave components of the wave field respectively (Drennan et al., 1999). Recent results from large eddy simulations over moving wave fields also suggest that, in developing sea conditions, waves are not expected to significantly influence turbulent winds at heights of more than about $10 \mathrm{~m}$ (Sullivan et al., 2014). In summary, the wave field is only expected to in- fluence the turbulent winds near the surface or in conditions where swell dominates the wave field.

High-frequency gas concentration measurements for studies of air-sea exchange have been shown to suffer significant motion-correlated biases resulting from the hydrostatic pressure change with vertical displacement (Miller et al., 2010) and potentially from mechanical sensitivities of the sensors themselves (McGillis et al., 2001; Yelland et al., 2009; Miller et al., 2010). These biases cause distortions of the cospectra between the vertical wind component and gas concentration (Edson et al., 2011) apparent in the cospectra at frequencies associated with the platform motion, and several recent studies have applied motion decorrelation algorithms to remove this signal (Miller et al., 2010; Edson et al., 2011; Blomquist et al., 2014).

Such an approach can also correct the apparent motionscale bias in the momentum flux but is controversial since, as discussed above, there are circumstances in which a real wave-correlated signal may be expected in the turbulence measurements. Here we present measurements which demonstrate a significant motion-scale feature in momentum flux measurements from a research ship. We show the impact of applying a simple regression procedure to remove the bias and provide evidence that suggests the source of the bias is time-varying flow distortion correlated with ship motion and attitude.

\section{Data}

The measurements were made on the RRS James Clark Ross as part of the Waves, Aerosol and Gas Exchange Study (WAGES), a programme of near-continuous measurements using the autonomous AutoFlux system (Yelland et al., 2009). Turbulent wind components were measured by a Gill R3 sonic anemometer installed above the forward, starboard corner of the ship's foremast platform (Fig. 1). The measurement volume was approximately $16.5 \mathrm{~m}$ above sea level. Platform motion was measured with a Systron Donner MotionPak Mk II, mounted rigidly at the base of the anemometer and sampled synchronously with it. Wave field measurements were made using a WAVEX X-band radar installed above the bridge top. The WAVEX system obtains directional wave spectra and mean wave parameters every $5 \mathrm{~min}$.

The fast-response instrumentation operated at $20 \mathrm{~Hz}$, and flux estimates were calculated over 30 min periods. The raw wind and motion measurements were first despiked and the wind components corrected for platform motion using the complementary filtering approach of Edson et al. (1998). The motion correction algorithm set out in Edson et al. (1998) and as usually applied corrects the measured horizontal winds for low-frequency horizontal motions (ship's underway velocity) in the earth frame. This neglects the aliasing of the ship's horizontal speed into the vertical imposed by the non-horizontal 


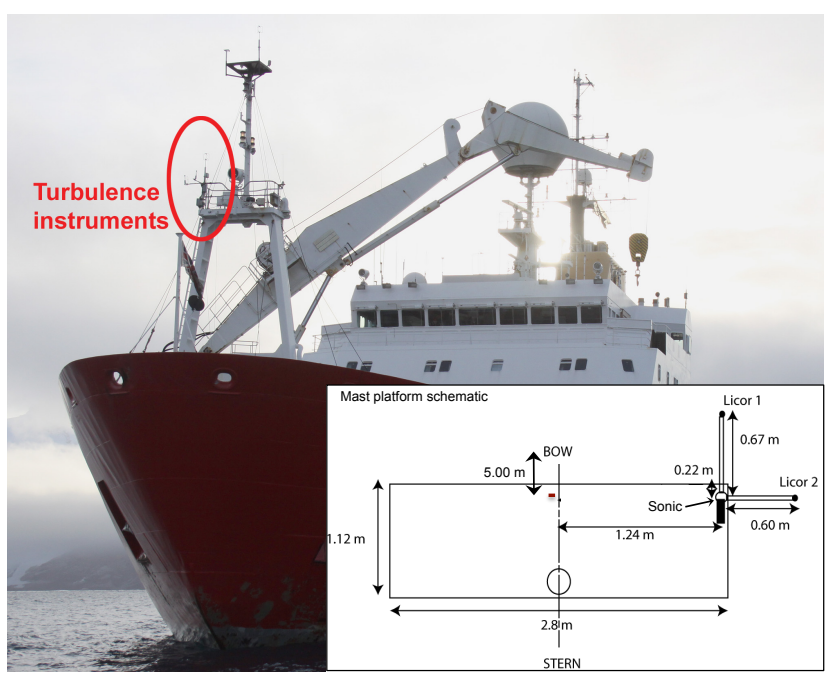

Figure 1. Locations of the flux instrumentation on the RRS James Clark Ross. The sonic anemometer is $2.0 \mathrm{~m}$ above the starboard forward corner of the platform. Note that the forecastle crane is generally stowed close to the deck while the ship is underway or on station.

mean streamline at the point of measurement due to flow distortion over the ship. The true vertical wind speed, $w_{\text {true }}$, is determined from the measured, motion-corrected vertical wind, $w_{\text {rel }}$, and the horizontal true and relative winds ( $U_{\text {true }}$ and $\left.U_{\text {rel }}\right)$ as

$w_{\text {true }}=w_{\text {rel }}-\left(\overline{w_{\text {rel }}} \times\left[1-\overline{U_{\text {true }}} / \overline{U_{\text {rel }}}\right]\right)$,

where an overbar indicates a time average (Tupman, 2013). The derivation of Eq. (1) and the impact of applying this correction are described in Appendix A. This correction addresses the same source of measurement error as that recently described by Landwehr et al. (2015), who address it by applying corrections for the ship's low-frequency horizontal velocity after rotating the ship-relative winds (corrected for high-frequency motions) into the reference frame of the mean streamline for each flux averaging period.

After motion correction, each $30 \mathrm{~min}$ record is rotated into a reference frame aligned with the mean streamline, wind components were linearly detrended and eddy covariance momentum fluxes calculated. CFD modelling of the air flow over the James Clark Ross was initially undertaken by Yelland et al. (2002) but only for flow on to the bow; we have extended the CFD study for a much wider range of relative wind directions and the results were used to determine direction-dependent corrections to the mean $(30 \mathrm{~min}$ averaged) relative wind speed and measurement height. The new CFD study is documented in Moat and Yelland (2015) and the primary results reproduced here in Appendix B. The modelled wind speed bias at the sensor location varied between -0.9 and $8.4 \%$ for wind directions between $20^{\circ}$ to port of the bow and $120^{\circ}$ to starboard, and the height by

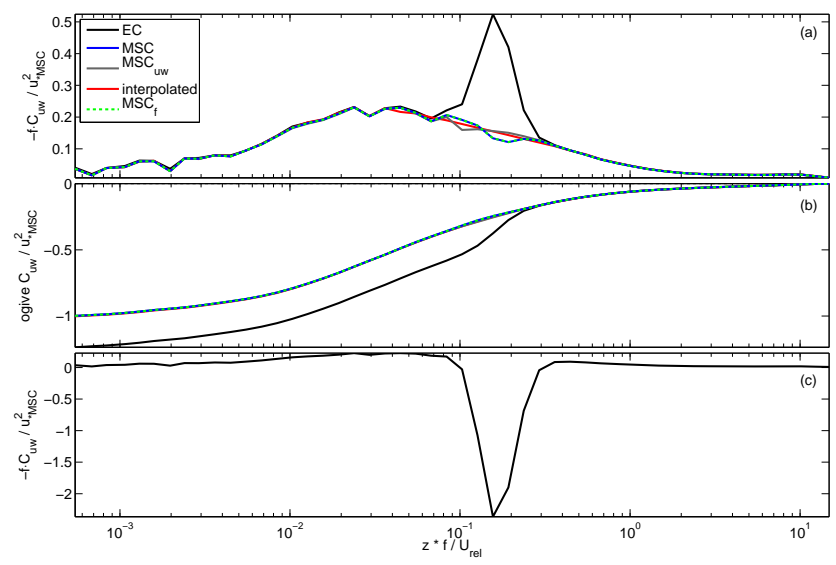

Figure 2. Frequency-weighted inverted and normalised momentum flux cospectra (a) and normalised ogives (b), shown relative to nondimensionalised frequency using measurement height $z$ and mean relative wind speed $U_{\text {rel }}$. Also shown are frequency-weighted, inverted and normalised cospectra calculated prior to motion correcting the turbulent velocity components, which results in a large upwards flux signal at the motion scale (c). Results shown are an average of $13130 \mathrm{~min}$ duration measurements at mean wind speeds $10 \mathrm{~ms}^{-1}<U_{10 \mathrm{n}}<14 \mathrm{~ms}^{-1}$. EC indicates the cospectra after removing platform motion following Edson et al. (1998) and shows the residual signal at scales typical of the wave field. The interpolation across the wave scales has been applied between frequencies of 0.04 and $0.4 \mathrm{~Hz}$. The motion-scale correction (MSC) can either be applied as per Eq. (2) (MSC), with Eq. (2) applied to both the along and vertical wind components $\left(\mathrm{MSC}_{\mathrm{uw}}\right)$, or as described by Edson et al. (2011) $\left(\mathrm{MSC}_{f}\right)$. Normalisation of the five different sets of results is by $u_{*}$ with MSC applied as per Eq. (2). Note that the $\mathrm{MSC}_{f}$ line overlies the MSC line at all frequencies, and the interpolated, $\mathrm{MSC}_{\mathrm{uw}}$ and $\mathrm{EC}$ lines overlie at frequencies away from the motion-scale.

which the flow was raised varied between 1.3 and $3.2 \mathrm{~m}$. Wind directions beyond $20^{\circ}$ to port of the bow were affected by small-scale obstructions on the foremast platform that are not included in the CFD model; these wind directions are thus excluded from the following analysis. After applying the corrections, the measured winds were corrected to $10 \mathrm{~m}$ height and neutral stability using the Businger-Dyer relationships (Businger, 1988) and the $10 \mathrm{~m}$ neutral drag coefficient, $\mathrm{CD}_{10 \mathrm{n}}$, was calculated from $U_{10}$ and the momentum flux estimates.

The measurements used here were obtained between 9 January and 16 August 2013 in locations throughout the North and South Atlantic, the Southern Ocean and the Arctic Ocean, at latitudes ranging from $62^{\circ} \mathrm{S}$ to $75^{\circ} \mathrm{N}$. After excluding measurement periods when the ship was within sea ice, there were 2920 individual flux estimates available for analysis. Flux estimates were then rejected from the analysis where there was excessive ship manoeuvring, where flux quality control criteria were failed (Foken and Wichura, 1996; Vickers and Mahrt, 1997) and when the air temperature 


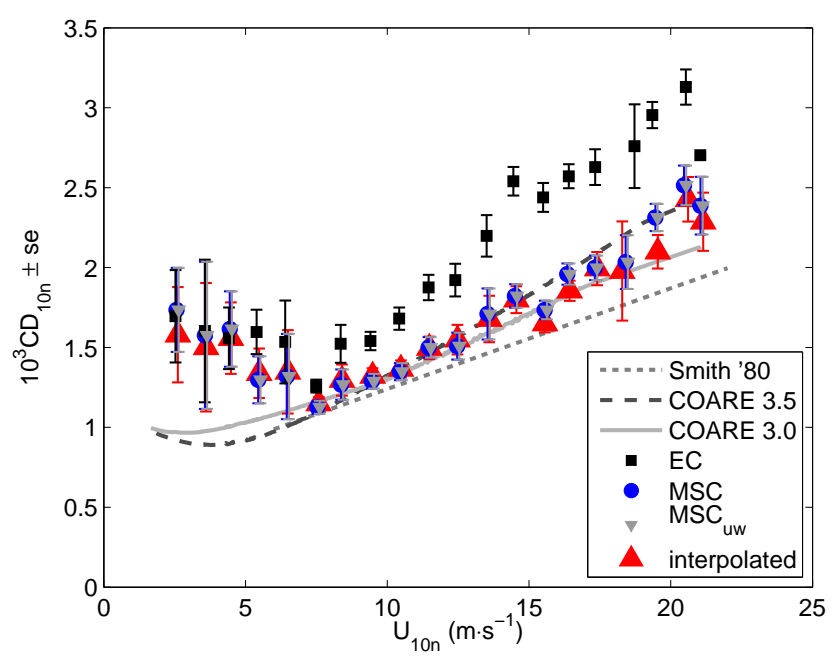

Figure 3. Drag coefficients bin-averaged by wind speed, relative to $U_{10 \mathrm{n}}(n=499)$. Four versions of the measurements are shown: without correction for wave-scale bias (EC); with correction applied to the vertical velocity only (MSC); correction applied to both vertical and horizontal velocity components $\left(\mathrm{MSC}_{\mathrm{uw}}\right)$; and correction via a simple interpolation across the wave-scale portion of the cospectra (interpolated). The bulk COARE 3.0 and 3.5 results are calculated without dependence on wave field or radiation.

was less than $2{ }^{\circ} \mathrm{C}$ when ice build-up may affect the sensors. Of the remaining 1054 flux estimates, 80 were removed as outliers $\left(\mathrm{CD}_{10 \mathrm{n}}>5 \times 10^{-3}\right)$. Unless otherwise indicated, mean relative wind direction limits of $20^{\circ}$ to port and $50^{\circ}$ to starboard of the bow were applied, a condition met by 499 flux estimates. Of the removed outliers, 38 lay within acceptable relative wind direction limits; of these, 6 were at winds speeds of $6 \mathrm{~m} \mathrm{~s}^{-1}$ or greater.

\section{Removal of the ship motion-scale signal}

Momentum flux cospectra and ogives for $U_{10}$ between 10 and $14 \mathrm{~m} \mathrm{~s}^{-1}$, normalised (by $f / u_{*}^{2}$ and $1 / u_{*}^{2}$ respectively, where $f$ is frequency ' and $u_{*}$ is the friction velocity) and averaged, are shown in Fig. 2. The cospectra and ogives differ from the typical forms obtained from experiments over land (e.g. Kaimal et al., 1972) at frequencies between approximately 0.06 and $0.25 \mathrm{~Hz}(0.09$ and 0.37 in the nondimensionalised frequency shown in Fig. 2), where a significant anomalous signal is present. These are frequencies associated with surface waves and with the platform motion that results; hence we term the cospectral signal at these frequencies the motion-scale signal.

At wind speeds above $7 \mathrm{~m} \mathrm{~s}^{-1}$, the $\mathrm{CD}_{10 \mathrm{n}}$ measurements are biased high compared with previous results (Fig. 3). The bias relative to the eddy-covariance-based parameterisation of Smith (1980) increases with wind speed from approximately $20 \%$ at $8 \mathrm{~m} \mathrm{~s}^{-1}$ to $60 \%$ at $20 \mathrm{~m} \mathrm{~s}^{-1}$. Note that the Smith (1980) parameterisation was derived from eddy covariance measurements made from a slim floating tower moored so as to minimise platform motion and induce minimal flow distortion. The bias is smaller when compared to the COARE 3.0 (Fairall et al., 2003) or COARE 3.5 (Edson et al., 2013) bulk algorithms.

The motion-scale signal can be removed from the vertical wind component to obtain a corrected vertical wind, $w_{\mathrm{MSC}}$, via a simple regression method:

$w_{\mathrm{MSC}}^{\prime}=w_{\text {true }}^{\prime}-\alpha_{1} \mathrm{acc}_{z}^{\prime}-\alpha_{2} \operatorname{vel}_{z}^{\prime}$,

where $\operatorname{acc}_{z}$ and $\mathrm{vel}_{z}$ are the platform's vertical acceleration and velocity, measured at the base of the sonic anemometer, and primes denote fluctuations determined from Reynolds' decomposition. The coefficients $\alpha_{1}$ and $\alpha_{2}$ are determined here by regression for each $30 \mathrm{~min}$ flux measurement period. This algorithm, which we term the motion-scale correction (MSC), is based on the regression corrections of Yelland et al. (2009) and Miller et al. (2010). It is also similar to the motion decorrelation algorithm given in a spectral formulation by Edson et al. (2011), originally utilised to remove motion biases from $\mathrm{CO}_{2}$ flux cospectra, and here termed the $\mathrm{MSC}_{f}$. The $\mathrm{MSC}_{f}$ algorithm coefficients are defined as the ratio of covariances of vertical wind and platform motion to variances of platform motion. The MSC and $\mathrm{MSC}_{f}$ methods give almost identical results (Fig. 2).

Applying the MSC algorithm removes the motion-scale signal (Fig. 2) and results in a 20 to $30 \%$ decrease in $\mathrm{CD}_{10}$ n for wind speeds above $7 \mathrm{~m} \mathrm{~s}^{-1}$ and absolute values similar to those of COARE 3.0 or 3.5 (Fig. 3). The signal removed is similar in size and of the same sign as the biases in shipbased momentum flux measurements reported by Edson et al. (1998) and Dupuis et al. (2003).

Applying the MSC to the along-wind component as well as the vertical component makes an insignificant $(\ll 1 \%)$ additional difference to the measured flux (shown as $\mathrm{MSC}_{\mathrm{uw}}$ in Figs. 2 and 3). Interpolating the measured cospectra across the motion-scale frequencies gives similar results to the MSC algorithm under most conditions (shown as "interpolated" in Figs. 2 and 3: Prytherch, 2011; Tupman, 2013). However, interpolation requires selection of appropriate frequencies to interpolate between, in this case, 0.04 and $0.4 \mathrm{~Hz}(0.06$ and 0.59 in the non-dimensionalised frequency shown in Fig. 2), and is not dependent on a physical variable related to the presumed source of the error (platform motion-dependent flow distortion). For these reasons, correction using the MSC algorithm is preferable.

\section{Discussion}

Following application of the MSC the cospectral shape matches the Kaimal form expected. This suggests that the motion-scale bias is being effectively removed. 
The MSC also results in drag coefficients that lie within the range of previous parameterisations. At the highest wind speeds (over $15 \mathrm{~m} \mathrm{~s}^{-1}$ ) the parameterisations begin to diverge significantly and the WAGES $\mathrm{CD}_{10}$ are larger than those given by Smith (1980) and lie between those of COARE 3.0 and 3.5. It should be noted that COARE 3.0 and 3.5 are both defined using wind speeds in the frame of reference of the surface currents (see Appendix in Edson et al., 2013) rather than in the earth frame of reference as used by Smith (1980). Surface current measurements were not available for the WAGES data. For surface currents aligned with the prevailing wind direction, adopting a surface current frame of reference would lead to a small apparent increase in the drag coefficients presented here.

While several previous studies have ascribed a high bias in drag coefficient estimates from ships to flow distortion (Edson et al., 1998, 2013; Pedreros et al., 2003), they have not examined the effect in detail. Inaccurate tilt estimation, a related source of error, may also contribute to this bias, particularly at low wind speeds (Landwehr et al., 2015). Few other studies have discussed such biases at all, and it seems likely that the severity of any motion-correlated bias is highly dependent on individual platforms and instrument installations in the same manner as the mean flow distortion. The bias is potentially worse here than in many other studies; the sonic anemometer is mounted lower on the foremast than would be ideal because the long-term measurement programme made it necessary to be able to service the instruments easily and without access to a crane. There are also a greater number of small-scale obstructions such as searchlights near to the measurement point than would be the case on lattice-style masts often deployed on dedicated flux measurement campaigns. Because the measurements are continuous and autonomous, a large fraction of our data is also obtained with the ship underway. In contrast, dedicated eddy covariance studies of air-sea exchange would usually focus almost exclusively on measurements made on station when ship motion is substantially less than when underway. Finally it is possible that such biases are present in some fraction of the measurements of many studies but are excluded from final analysis by quality control procedures without a close examination of the bias being made. Many studies with modest data volumes have quality controlled the individual flux estimates via a visual inspection of the ogive curves, rejecting those that do not closely match the expected form (e.g. Fairall et al., 1997; Norris et al., 2012).

As discussed in Sect. 1 above, there is evidence from previous studies that the influence of the wave field on the turbulent winds should be small, at heights above some limit which is assumed to be related to the wave properties: values between 4 and $10 \mathrm{~m}$ have been cited (Miller et al., 2008; Sullivan et al., 2014). The Sullivan et al. (2014) results correspond to a height of the order of 1.5 times the significant wave height. Real wave effects are thus expected to be negligible for typical measurement heights of ship-based sen-
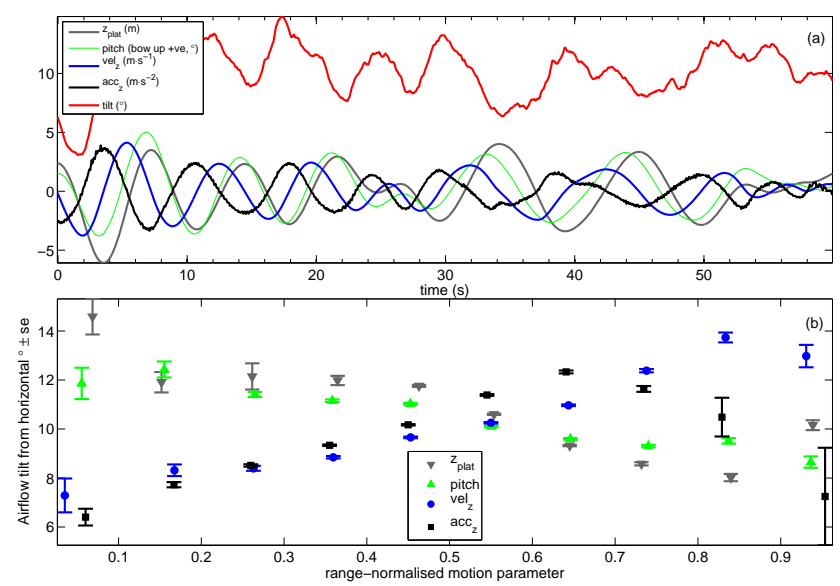

Figure 4. (a) Time series (60s) of vertical platform displacement, velocity and acceleration, platform pitch and tilt from horizontal of the streamwise airflow measured by the AutoFlux anemometer. The tilt has been smoothed with a 40-sample moving average. The measurements are sampled from a period (23 April 2013, 21:0021:30 UTC) with near bow-on winds and mean $U_{10 \mathrm{n}}$ of $15.2 \mathrm{~m} \mathrm{~s}^{-1}$. (b) Variation of the tilt of streamwise airflow from horizontal, relative to the vertical platform displacement, velocity, acceleration and platform pitch each normalised by their measured range. Tilt averages were made over the $30 \mathrm{~min}$ period that the measurements in (a) were sampled from.

sors $(15-20 \mathrm{~m})$ under most conditions. Below we provide more direct evidence that the wave-scale signal seen in the WAGES data is due, in large part at least, to the effects of flow distortion over a moving platform.

\subsection{Motion dependence of the streamline}

The angle to the horizontal of the airflow measured at the sonic anemometer site was found to be dependent on the vertical motion of the ship (Fig. 4). Perturbations in the tilt of the streamline are approximately in phase with $\operatorname{acc}_{z}$, out of phase with the vertical displacement and pitch, and lead $\mathrm{vel}_{z}$ by about $90^{\circ}$. There are multiple processes that may affect the streamline orientation as the ship moves over the waves:

- Vertical displacement of the ship changes the vertical extent of the obstacle that the ship presents to the flow and the relative height of the measurement volume with respect to that of the bow above the water line.

- The ship's pitch similarly changes both the effective size of the obstacle presented to the flow and the relative location of the sonic anemometer within the distorted flow above the bow.

- Vertical motion of the ship will force the overlying air to move.

In the example here for $15 \mathrm{~m} \mathrm{~s}^{-1}$, bow-on winds, the airflow tilt varies by about $\pm 3^{\circ}$ around a mean of approximately 


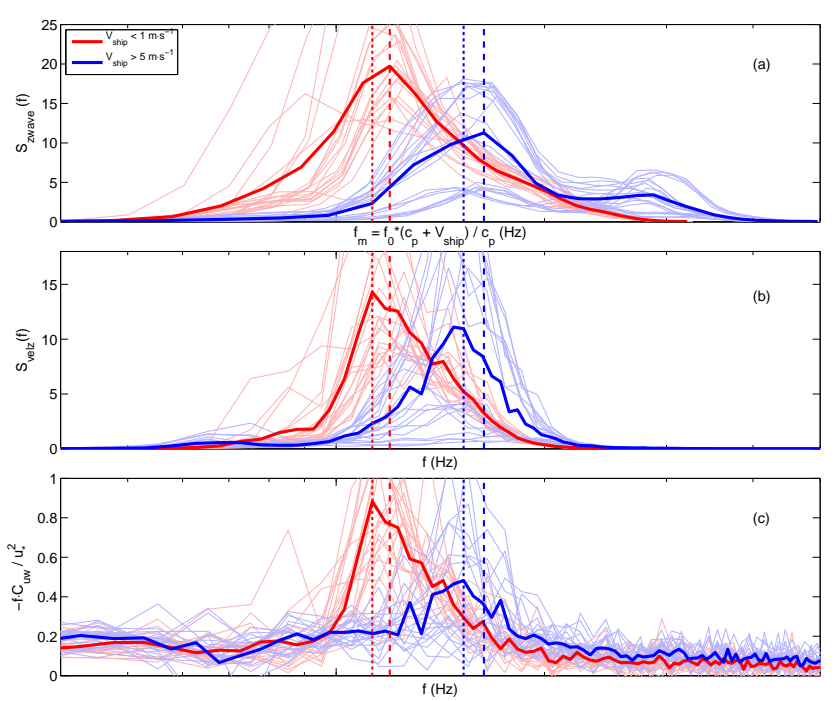

Figure 5. Comparison of averaged spectra. In all panels two sets of averaged data are compared: periods when the ship was stationary ( $V_{\text {ship }}<1 \mathrm{~ms}^{-1}, 21$ periods) and periods when the ship was steaming ( $V_{\text {ship }}>5 \mathrm{~m} \mathrm{~s}^{-1}, 20$ periods); the individual spectra are shown as pale lines for reference. For all measurements, $U_{10}$ was between 10 and $12 \mathrm{~ms}^{-1}$. (a) Spectral density of non-directional wave heights from WAVEX with frequency shifted to the reference frame of the moving ship; (b) spectral density of platform vertical velocity as measured on the foremast; (c) frequency-weighted inverted cospectral density for the momentum flux (positive upwards) - turbulent velocity components are motion corrected, but the MSC correction is not applied. The dashed vertical lines indicate the peak frequency of the wave spectrum; dotted vertical lines indicate the peak frequency of the momentum flux cospectra in (c). Note that the axis limits are set very close to the scale of the ship motion to allow details to be seen clearly.

$10^{\circ}$. The various parameters shown in Fig. 4a are all interdependent, but streamline tilt showed slightly more consistent trends with the velocity and acceleration parameters than with displacement or pitch, suggesting that "pumping" of the air above the moving deck may be the dominant effect.

\subsection{Characteristic frequencies of spectral features}

For a platform moving through a wave field aligned with the direction of travel, it would be expected that the frequency of ship motion forced by the waves would differ from that for a ship on station with no mean horizontal velocity. The change could be of either sign depending on the ratio of wavelength to the length of the ship, with an increase in frequency for wavelengths much longer than the ship. The measured frequency of atmospheric turbulent structures would also be shifted to higher frequencies relative to those measured when on station. The nature of the frequency shift should differ for turbulent air motions, which advect with the wind and have a ship-relative velocity equal to the sum of wind and ship speeds, and wave-correlated features in the turbulence field, which are phase-locked to the surface waves (Sullivan et al., 2000, 2008, 2014), and will have a ship-relative velocity of the sum of wave-phase and ship speeds. A signal due to real wind-wave interaction should thus appear at a different frequency to that from a ship-motion-induced measurement bias.

Figure 5 shows a comparison of the power spectral density of platform vertical velocity ( $S_{\text {velz }}$, Fig. $5 \mathrm{~b}$ ) and frequency weighted cospectral densities for the streamwise momentum flux (normalised by $u_{*}$ ) both for periods during which the ship was on station ( $V_{\text {ship }}<1 \mathrm{~m} \mathrm{~s}^{-1}$, where $V_{\text {ship }}$ is the speed of the ship) and when underway $\left(V_{\text {ship }}>5 \mathrm{~m} \mathrm{~s}^{-1}\right)$. The cospectra are shown after applying the standard motion correction to the measured turbulent velocity components but without applying the MSC correction. Also shown are the spectral densities of the surface wave field (Fig. 5a). The wave radar provides wave spectra in the earth frame, corrected for ship speed; in order to compare these directly with the measured turbulence and ship-motion spectra when underway, we need to transform them into a reference frame moving with the ship. This is achieved by plotting against a modified frequency, $f_{\mathrm{m}}=f_{0}\left(c_{\mathrm{p}}+V_{\text {ship }}\right) / c_{\mathrm{p}}$, where $f_{\mathrm{m}}$ is the frequency that would be measured in the ship reference frame and $f_{0}$ is the true frequency in the earth frame. The periods chosen all have bow-on winds, wind speeds of between 10 and $12 \mathrm{~m} \mathrm{~s}^{-1}$ and similar sea states: the (true) mean peaks of the mean WAVEX-derived non-directional wave spectra $\left(S_{z \text { wave }}\right)$ are 0.120 and $0.110 \mathrm{~Hz}$, and mean significant wave heights are 4.73 and $3.51 \mathrm{~m}$ for the stationary and underway periods respectively.

For the on-station measurements, the peak in the momentum flux cospectra (no MSC, Fig. 5c) is at $0.113 \mathrm{~Hz}$, which matches that of the peak in ship vertical velocity (Fig. 5b) and is at slightly lower frequency than the peak in the ship-frame surface wave spectra $(0.120 \mathrm{~Hz}$, Fig. 5a). For the underway cases the peak in the ship-frame wave spectra is shifted to higher frequency $(0.163 \mathrm{~Hz})$ compared to the true spectra. The peak in the ship motion spectrum $(0.148 \mathrm{~Hz})$ is again lower than that of the wave spectrum and by a larger margin than for the on-station case. The peak in the momentum flux cospectrum at $0.153 \mathrm{~Hz}$ is much closer to that of the ship motion than that of the wave spectrum.

The correspondence of the peak in momentum flux cospectra with that of the ship motion rather than that of the wave field suggests that the residual signal after motion correction is an artefact of motion-correlated flow distortion rather than a result of a real wave-correlated signal in the turbulence.

\subsection{Directional dependence of drag coefficient bias}

Mean flow distortion is strongly dependent on relative wind direction (Yelland et al., 1998), even for a motionless ship with zero pitch and roll angles. The dependence of the calculated drag coefficients on relative wind direction before and 

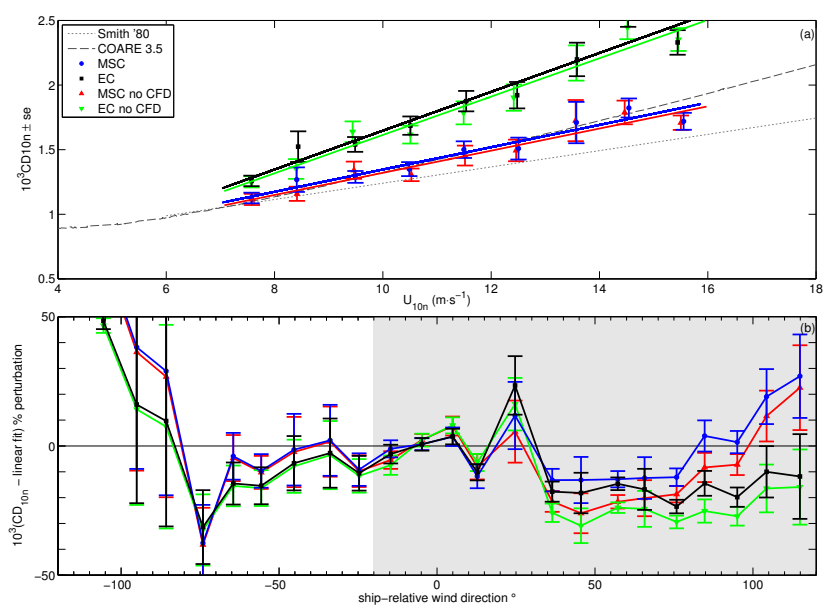

Figure 6. (a) Measurements either without correction for wavescale bias (EC) or with correction applied to the vertical velocity only (MSC) for wind speeds $7 \mathrm{~m} \mathrm{~s}^{-1}<U_{10 \mathrm{n}}<16 \mathrm{~m} \mathrm{~s}^{-1}(n=335)$ and relative wind directions between -20 and $+50^{\circ}$ (where a wind on the bow is at $0^{\circ}$ ). Lines are linear fits to the measurements. (b) variation of the difference between measured drag coefficients and the linear fits against relative wind direction for the same wind speed criteria $(n=663)$. Both panels also show measurements (with and without MSC) which have not had CFD-derived corrections to mean wind speed and height applied. Note that CFD corrections were only applied for the shaded range.

after applying the MSC algorithm is shown in Fig. 6. First, a linear fit was made between the drag coefficient and wind speed data obtained for wind directions between -20 and $+50^{\circ}$ of the bow. Then the drag coefficient anomalies (individual minus fit) were calculated and averaged into $10^{\circ}$ relative wind direction bins, and the results were plotted against relative wind direction. It can be seen that prior to applying the MSC algorithm, the drag coefficient anomalies have a significant dependence on relative wind direction and that application of the algorithm significantly reduces this dependence. For completeness the results are also shown without first applying the direction-dependent CFD-derived correction to the mean $30 \mathrm{~min}$ averaged wind speed; this also reduces the dependence of the drag coefficient on relative wind direction.

Application of the MSC and the mean CFD correction does not completely remove all dependence of the drag coefficient on relative wind direction. This suggests that one or both corrections may need refinement. In the case of the MSC algorithm, the effect of the roll of the ship is likely to become significant when the wind direction is beam-on rather than bow-on. In the case of the CFD correction to the mean wind speed, the model of the ship geometry may have to be refined to take into account local flow distortion caused by small objects mounted on the foremast, close to the anemometer. These are areas for future investigation.

\section{Conclusions}

Methods for removal of motion-correlated signals from fastresponse gas measurements made onboard moving platforms have become more commonly applied in recent years; however, these techniques remain controversial when applied to fast-response winds for the purpose of momentum flux calculation. The results here demonstrate these methods and their impact on ship-based momentum flux measurements where a significant motion-correlated bias is present in the motion-corrected cospectra. The motion-correlated signals are shown to be dependent on platform velocity relative to the wave field. In addition, the dependence of the flux on wind direction relative to the ship is reduced after applying the correction methods. These results suggest that the motioncorrelated signal is due to the effects of time-varying flow distortion. Further investigation is required to resolve the details of the physical processes involved.

The recent revision of the COARE bulk flux algorithm (COARE 3.5, Edson et al., 2013) is determined only from data from platforms other than ships (buoys, towers, FLIP). These data all require motion correction, and Bigorre et al. (2013) report biases of a few percent in mean wind speed due to flow distortion around one of the buoys used to collect data at high wind speed, but these platforms generally do not suffer such significant flow distortion problems as ships.

For many applications, ship-based measurements are the only option; for example, direct eddy covariance measurements of gas transfer require instrumentation that can only realistically be operated on a ship. A means of effectively dealing with biases induced by flow distortion around a moving platform is thus essential. The methods demonstrated above provide a successful correction; after its application the shape of the cospectra matches the Kaimal form expected and our drag coefficient results lie within the range of recent leading parameterisations. 


\section{Appendix A: Underway vertical wind speed}

The motion correction algorithm of Edson et al. (1998) calculates a total platform velocity in the earth frame as the sum of high-pass filtered wave-induced motions, obtained from the integration of accelerometers, and low-pass filtered velocities (the platform's underway motion). The latter are applied only in the horizontal since the mean vertical velocity is 0 by definition. The corrected winds in the earth frame are obtained as the vector sum of measured and platform velocities. This neglects the impact of flow distortion on the measured winds (Fig. A1). At the point of measurement on the foremast of a ship, the mean flow is forced to lift, resulting in a streamline tilted upwards from the horizontal. The measured along-streamline wind depends upon ship velocity as well as earth-relative wind. Since the streamline is tilted, a fraction of the ship velocity affects the measured vertical as well as the horizontal winds in the earth frame and must be corrected.

When conditions are stationary (an implicit assumption for direct flux measurement) the measured, motion-corrected vertical wind, $w_{\text {rel }}$, can be corrected for the horizontal platform mean velocity to obtain the true vertical wind speed $w_{\text {true }}$. The ratio of the mean true to mean relative vertical winds is equal to the ratio of the mean true to mean relative horizontal winds, i.e.

$\overline{\frac{U_{\text {true }}}{U_{\text {rel }}}}=\frac{\overline{w_{\text {true }}}}{\overline{w_{\text {rel }}}}$

(Fig. A1). Then, as

$w_{\text {true }}=w_{\text {rel }}-\left(\overline{w_{\text {rel }}}-\overline{w_{\text {true }}}\right)$,

$w_{\text {true }}$ can be determined via Eq. (1),

$w_{\text {true }}=w_{\text {rel }}-\left(\overline{w_{\text {rel }}} \times\left[1-\overline{U_{\text {true }}} / \overline{U_{\text {rel }}}\right]\right)$.

Note that this affects the mean vertical wind only and not the high-frequency perturbations; however, failure to account for the impact of flow distortion on the vertical wind measurements would result in the streamline orientation being incorrectly calculated and both $u^{\prime}$ and $w^{\prime}$ values being biased after rotation into the streamline-oriented reference frame in which the fluxes are calculated. We also note that at low wind speeds $\left(\sim<5 \mathrm{~ms}^{-1}\right)$, the determination of the reference frame for a particular measurement interval may be biased by offsets in the vertical wind speed, leading to errors in the tilt calculation (Wilczak et al., 2001; Landwehr et al., 2015).

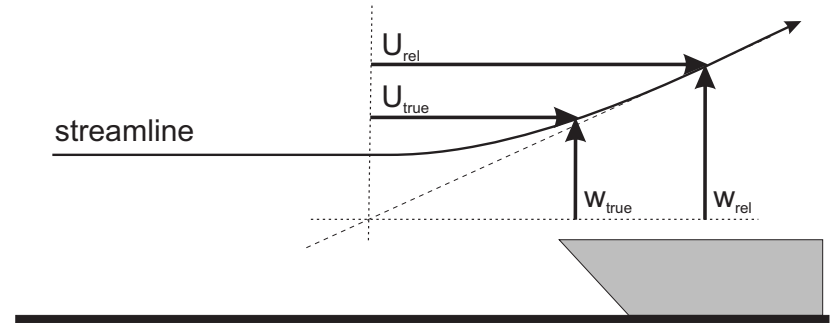

Figure A1. Schematic of the impact of ship horizontal velocity on non-horizontal airflow. The measured horizontal $\left(U_{\text {rel }}\right)$ and vertical $\left(w_{\text {rel }}\right)$ wind components must both be corrected for ship velocity to obtain the true wind components. Not correcting the measured vertical wind will result in an incorrect determination of the tilt angle of the flow from horizontal.

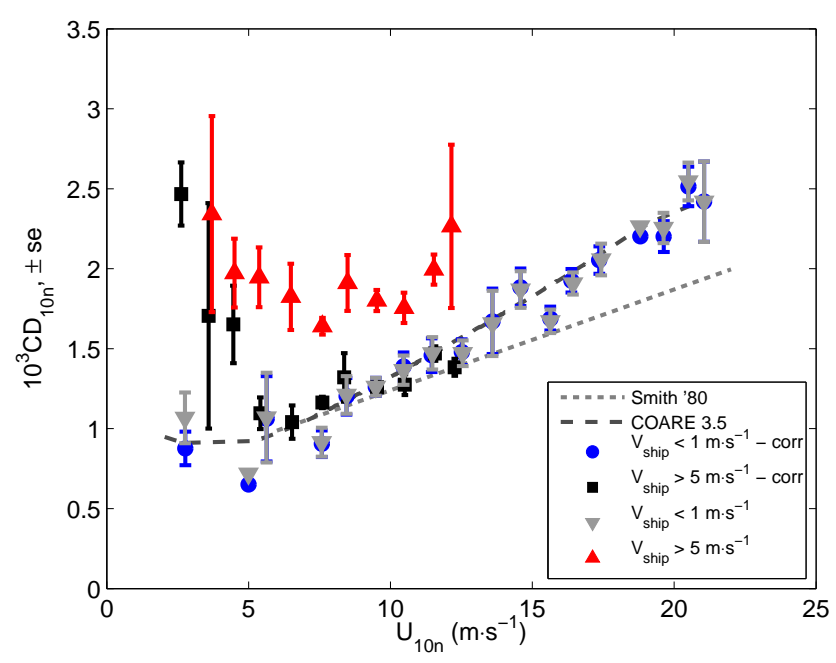

Figure A2. Wind speed-averaged drag coefficients, relative to $U_{10 \mathrm{n}}$. Two sets of measurements are compared: where the ship was deemed stationary $\left(V_{\text {ship }}<1 \mathrm{~ms}^{-1}, n=233\right.$ ) and where the ship was underway $\left(V_{\text {ship }}>5 \mathrm{~ms}^{-1}, n=182\right)$. The measurements are shown with ("corr") and without the vertical wind speed corrected as per Eq. (1).

The effectiveness of this correction is demonstrated through comparison of drag coefficients from periods when the ship was stationary $\left(V_{\text {ship }}<1 \mathrm{~m} \mathrm{~s}^{-1}\right)$ and underway $\left(V_{\text {ship }}>5 \mathrm{~m} \mathrm{~s}^{-1}\right)$. Prior to correction, measurements from the underway ship are biased high relative to the stationary measurements (Fig. A2). Following correction, the stationary and underway measurements are in very good agreement for all but the very lowest wind speeds. Furthermore, for stationary periods (where the effect is small), the corrected and uncorrected results are also in good agreement. 


\section{Appendix B: CFD corrections for flow distortion}

The relative wind-direction-dependent CFD corrections for the mean flow distortion over the ship are given in Table B1. These are strictly valid only for the location of our sonic anemometer ( $1.24 \mathrm{~m}$ to starboard, $16.5 \mathrm{~m}$ above the waterline and $5.0 \mathrm{~m}$ aft of the bow) but should be broadly representative for nearby locations and indicative of the directionally dependent flow distortion that might be expected on any similar installation on other ships.
Table B1. Variation of wind speed bias and vertical flow displacement with relative wind direction, determined at the location of the AutoFlux anemometer (height above sea level, $z, 16.5 \mathrm{~m}$ ). The wind speed bias and $\Delta z$ are relative to a free stream location $2 \mathrm{~s}$ upstream of the anemometer site (after Yelland et al., 2002). A negative relative wind direction indicates a flow over the port side. Further details are given in Moat and Yelland (2015).

\begin{tabular}{rrr}
$\begin{array}{r}\text { Relative wind } \\
\text { direction }\left(^{\circ}\right)\end{array}$ & $\begin{array}{r}\text { Wind speed bias } \\
\text { at } z-\Delta z(\%)\end{array}$ & $\begin{array}{c}\Delta z \\
(\mathrm{~m})\end{array}$ \\
\hline-20 & 2.98 & 1.44 \\
-10 & 0.41 & 1.35 \\
0 & -0.39 & 1.32 \\
10 & -0.86 & 1.41 \\
20 & 0.7 & 1.54 \\
30 & 2.92 & 1.76 \\
50 & 5.11 & 2.27 \\
70 & 4.86 & 2.73 \\
90 & 8.35 & 2.96 \\
110 & 6.97 & 3.15 \\
\hline
\end{tabular}


Acknowledgements. WAGES was funded by the Natural Environment Research Council (grant numbers NE/G00353X/1 and NE/G003696/1). We would like to thank the two captains and crews of the RRS James Clark Ross and the ship logistics support staff at the British Antarctic Survey for their help throughout the project. We would also like to acknowledge helpful and ongoing technical discussions with S. Landwehr and B. Ward (University of Galway) that have contributed to this research.

Edited by: R. MacKenzie

\section{References}

Bigorre, S. P., Weller, R. A., Edson, J. B., and Ware, J. D.: A Surface Mooring for Air-Sea Interaction Research in the Gulf Stream. Part II: Analysis of the Observations and Their Accuracies, J. Atmos. Oceanic Technol., 30, 450-469. doi:10.1175/JTECH-D12-00078.1, 2013.

Blomquist, B. W., Huebert, B. J., Fairall, C. W., Bariteau, L., Edson, J. B., Hare, J. E., and McGillis, W. R.: Advances in air-sea $\mathrm{CO}_{2}$ flux measurement by eddy correlation, Bound.-Lay. Meteorol., 152, 245-276, doi:10.1007/s10546-014-9926-2, 2014.

Brooks, I. M.: Spatially Distributed Measurements of Platform Motion for the Correction of Ship-Based Turbulent Fluxes, J. Atmos. Ocean. Tech., 25, 2007-2017, doi:10.1175/2008JTECHA1086.1, 2008.

Brut, A., Butet, A., Durand, P., Caniaux, G., and Planton, S.: Airsea exchanges in the equatorial area from the EQUALANT99 dataset: Bulk parameterizations of turbulent fluxes corrected for airflow distortion, Q. J. Roy. Meteorol. Soc., 131, 2497-2538, doi:10.1256/qj.03.185, 2005.

Businger, J. A.: A note on the Businger-Dyer profiles, Bound.Lay. Meteorol., 42, 145-151, doi:10.1007/978-94-009-29357_11, 1988.

Deleonibus, P.: Momentum flux and wave spectra observations from an ocean tower, J. Geophys. Res., 76, 6506-6527, doi:10.1029/JC076i027p06506, 1971.

Drennan, W., Kahma, K., and Donelan, M.: On momentum flux and velocity spectra over waves, Bound.-Lay. Meteorol., 92, 489515, doi:10.1023/A:1002054820455, 1999.

Dupuis, H., Geurin, D., Hauser, D., Weill, A., Nacass, P., Drennan, W. M., Cloche, S., and Graber, H. C.: Impact of flow distortion corrections on turbulent fluxes estimated by the inertial dissipation method during the FETCH experiment on R/V L'Atalante, J. Geophys. Res., 108, 8064, doi:10.1029/2001JC001075, 2003.

Edson, J. B., Hinton, A. A., Prada, K. E., Hare, J. E., and Fairall, C. W.: Direct covariance flux estimates from mobile platforms at sea, J. Atmos. Ocean. Tech., 15, 547-562, doi:10.1175/15200426(1998)015<0547:DCFEFM>2.0.CO;2, 1998.

Edson, J. B., Fairall, C. W., Bariteau, L., Zappa, C. J., CifuentesLorenzen, A., McGillis, W. R., Pezoa, S., Hare, J. E., and Helmig, D.: Direct covariance measurement of $\mathrm{CO}_{2}$ gas transfer velocity during the 2008 Southern Ocean Gas Exchange Experiment: Wind speed dependency, J. Geophys. Res., 116, C00F10, doi:10.1029/2011JC007022, 2011.

Edson, J. B., Venkata Jampana, V., Weller, R. A., Bigorre, S. P., Plueddemann, A. J., Fairall, C. W., Miller, S. D., Mahrt, L., Vickers, D., and Hersbach, H.: On the exchange of momen- tum over the open ocean, J. Phys. Oceanogr., 43, 1589-1610, doi:10.1175/JPO-D-12-0173.1, 2013.

Fairall, C. W., White, A. B., Edson, J. B., and Hare, J. E.: Integrated shipboard measurements of the marine boundary layer, J. Atmos. Ocean. Tech., 14, 338-359, doi:10.1175/15200426(1997)014<0338:ISMOTM>2.0.CO;2, 1997.

Fairall, C. W., Bradley, E. F., Hare, J. E., Grachev, A. A., and Edson, J. B.: Bulk parameterization of air-sea fluxes: Updates and verification for the COARE algorithm, J. Climate, 16, 571-591, doi:10.1175/1520-0442(2003)016<0571:BPOASF>2.0.CO;2, 2003.

Foken, T. and Wichura, B.: Tools for quality assessment of surfacebased flux measurements 1, Agr. For. Meteorol., 78, 83-105, doi:10.1016/0168-1923(95)02248-1, 1996.

Kaimal, J. C., Izumi, Y. J., Wyngaard, C., and Cote, R.: Spectral characteristics of surface-layer turbulence, Q. J. Roy. Meteorol. Soc., 98, 563-589, doi:10.1002/qj.49709841707, 1972.

Landwehr, S., O’Sullivan, N., and Ward, B.: Direct Flux Measurements from Mobile Platforms at Sea: Motion and Air-Flow Distortion Corrections Revisited, J. Atmos. Ocean. Tech., 32, 11631178, doi:10.1175/JTECH-D-14-00137.1, 2015.

McGillis, W. R., Edson, J. B., Hare, J. E., and Fairall, C. W.: Direct covariance air-sea $\mathrm{CO}_{2}$ fluxes, J. Geophys. Res.-Oceans, 106, 16729-16745, doi:10.1029/2000JC000506, 2001.

Miller, S. D., Hristov, T. S., Edson, J. B., and Friehe, C. A.: Platform motion effects on measurements of turbulence and air-sea exchange over the open ocean, J. Atmos. Ocean. Tech., 25, 16831694, doi:10.1175/2008JTECHO547.1, 2008.

Miller, S. D., Marandino, C., and Saltzman, E. S.: Ship-based measurement of air-sea $\mathrm{CO}_{2}$ exchange by eddy covariance, J. Geophys. Res.-Atmos., 115, D02304, doi:10.1029/2009JD012193, 2010.

Moat, B. I. and Yelland, M. J.: Airflow distortion at instrument sites on the RRS James Clark Ross during the WAGES project. National Oceanography Centre, Southampton, UK Internal Document No. 12, available at: http://eprints.soton.ac.uk/373216/, last access: 16 January 2015.

Moat, B. I., Yelland, M. J., Pascal, R. W., and Molland, A. F.: An overview of the airflow distortion at anemometer sites on ships, Int. J. Climatol., 25, 997-1006, doi:10.1002/joc.1177, 2005.

Moat, B. I., Yelland, M. J., and Molland, A. F.: Quantifying the airflow distortion over merchant ships. Part II: application of the model results, J. Atmos. Ocean. Tech., 23, 351-360, doi:10.1175/JTECH1859.1, 2006a.

Moat, B. I., Yelland, M. J., Pascal, R. W., and Molland, A. F.: Quantifying the airflow distortion over merchant ships. Part I: validation of a CFD model, J. Atmos. Ocean. Tech., 23, 341-350, doi:10.1175/JTECH1858.1, 2006b.

Norris, S. J., Brooks, I. M., Hill, M. K., Brooks, B. J., Smith, M. H., and Sproson, D. A. J.: Eddy Covariance Measurements of the Sea Spray Aerosol Flux over the Open Ocean, J. Geophys. Res., 117, D07210, doi:10.1029/2011JD016549, 2012.

O'Sullivan, N., Landwehr, S., and Ward, B.: Mapping flow distortion on oceanographic platforms using computational fluid dynamics, Ocean Sci., 9, 855-866, doi:10.5194/os-9-855-2013, 2013.

O'Sullivan, N., Landwehr, S., and Ward, B.: Air-flow distortion and wave interactions: An experimental and numerical comparison, 
Methods Oceanogr., 12, 1-17, doi:10.1016/j.mio.2015.03.001, 2015.

Pedreros, R., Dardier, G., Dupuis, H., Graber, H. C., Drennan, W. M., Weill, A., Geurin, C., and Nacass, P.: Momentum and heat fluxes via the eddy correlation method on the R/V L'Atalante and an ASIS buoy, J. Geophys. Res., 108, C11, doi:10.1029/2002JC001449, 2003.

Popinet, S., Smith, M., and Stevens, C.: Experimental and numerical study of turbulence characteristics of airflow around a research vessel, J. Atmos. Ocean. Tech., 21, 1575-1589, doi:10.1175/1520-0426(2004)021<1575:EANSOT>2.0.CO;2, 2004.

Prytherch, J.: Measurement and parameterisation of the air-sea $\mathrm{CO}_{2}$ flux in high winds, PhD thesis, University of Southampton, 2011.

Schulze, E. W., Sanderson, B. G., and Bradley, E. F.: Motion correction for shipborne turbulence sensors, J. Atmos. Ocean. Tech., 22, 44-69, doi:10.1175/JTECH-1685.1, 2005.

Smith, S.: Wind stress and heat flux over the ocean in gale force winds, J. Phys. Oceanogr., 10, 709-726, doi:10.1175/15200485(1980)010<0709:WSAHFO>2.0.CO;2, 1980.

Sullivan, P. P., McWilliams, J. C., and Moeng, C.-H.: Simulation of turbulent flow over idealized water waves, J. Fluid. Mech., 404, 47-85, doi:10.1017/S0022112099006965, 2000.

Sullivan, P. P., Edson, J. B., Hristov, T., and McWilliams, J. C.: Large-eddy simulations and observations of atmospheric marine boundary layers above non-equilibrium surface waves, J. Atmos. Sci., 65, 1225-1245, doi:10.1175/2007JAS2427.1, 2008.

Sullivan, P. P., McWilliams, J. C., and Patton, E. G.: Large-Eddy Simulation of Marine Atmospheric Boundary Layers above a Spectrum of Moving Waves, J. Atmos. Sci., 71, 4001-4027, doi:10.1175/JAS-D-14-0095.1, 2014.
Tupman, D. J.: Air-sea flux measurements over the Southern Ocean, $\mathrm{PhD}$ thesis, University of Leeds, 2013.

Vickers, D. and Mahrt, L.: Quality control and flux sampling problems for tower and aircraft data, J. Atmos. Ocean. Tech., 14, 512-526, doi:10.1175/15200426(1997)014<0512:QCAFSP>2.0.CO;2, 1997.

Weill, A., Eymard, L., Caniaux, G., Hauser, D., Planton, S., Dupuis, H., Brut, A., Guerin, C., Nacass, P., Butet, A., Cloché, S., Perderos, R., Durand, P., Bourras, D., Giordani, H., Lachaud, G., and Bouhours. G.: Toward a Better Determination of Turbulent Air-Sea Fluxes from Several Experiments, J. Climate, 16, 600-618, doi:10.1175/15200442(2003)016<0600:TABDOT>2.0.CO;2, 2003.

Wilczak, J., Oncley, S., and Stage, S.: Sonic anemometer tilt correction algorithms, Bound.-Lay. Meteorol., 99, 127-150, doi:10.1023/A:1018966204465, 2001.

Yelland, M. J., Moat, B. I., Taylor, P. K., Pascal, R. W., Hutchings, J., and Cornell, V. C.: Wind stress measurements from the open ocean corrected for airflow distortion by the ship, J. Atmos. Ocean. Tech., 28, 1511-1526, doi:10.1175/15200485(1998)028<1511:WSMFTO>2.0.CO;2, 1998.

Yelland, M. J., Moat, B. I., Pascal, R. W., and Berry, D. I.: CFD model estimates of the airflow distortion over research ships and the impact on momentum flux measurements, J. Atmos. Ocean. Tech., 19, 1477-1499, doi:10.1175/15200426(2002)019<1477:CMEOTA>2.0.CO;2, 2002.

Yelland, M., Pascal, R., Taylor, P., and Moat, B.: AutoFlux: an autonomous system for the direct measurement of the air-sea fluxes of $\mathrm{CO}_{2}$, heat and momentum. J. Operation. Oceanogr., 2, 15-23, doi:10.1080/1755876X.2009.11020105, 2009. 